\title{
A NEW SPECIES OF CONICEROMYIA FROM CUBA
} (DIPTERA; PHORIDÆ. $)^{1}$

\section{By Charles T. Brues.}

In 1923 Borgemeier described from South America a remarkable genus of Phoridæ to which he gave the name of Coniceromyia. It is characterized by the extremely elongated, pointed antennæ of the male which bear an apical arista. The male also has the front tibiæ remarkably modified in the type species, with a large bristle near the base followed by a deep emargination of the tibia. Later ('24) he added two other species, one of which has the front tarsi much flattened in the male, with a long, finger-like process extending from the edge of the basal joint. Furthermore, the costal vein is strongly thickened in both sexes.

Recently while in Cuba at the Harvard Biological Laboratory, I had an opportunity to visit the San Juan Mountains, which lie to the southeast of Soledad where the laboratory is located. In the material collected there I find a species of Coniceromyia, represented by both sexes, quite different from any of the South American forms.

It may be distinguished as follows:

\section{Key to the Species of Coniceromyia.}

1. Anterior tibia with a series of three large stout bristles on the basal half; front tarsi of male greatly widened, the first joint with a long slender projection from its edge near apex (Fig. 1, b) ........... cubensis sp. nov.

Anterior tibia with only one large bristle, placed before the middle, or with two in this position.............2.

2. Thorax dark fuscous in color, anterior tibia with a series of two bristles before the middle........ . fusca Borgm. Thorax yellowish or ferruginous, anterior tibia with a single large bristle before the middle, sometimes with a much smaller one immediately next to it...............

${ }^{1}$ Contribution from the Entomological Laboratory of the Bussey Institution, Harvard University, no. 300 
3. Dorsal face of anterior tibia of the male with a series of seven small bristles forming a series between the large bristle and the apex; first tarsal joint with a long slender projection from its edge. ............ . anacleti Borgm. Dorsal surface of anterior tibia of male without a series of bristles in this position........... epicantha Borgm.

Coniceromyia cubensis sp. nov.

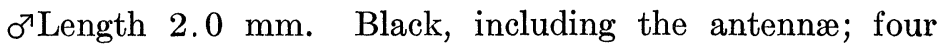
posterior femora piceous; front legs and all tibiæ and tarsi yel-
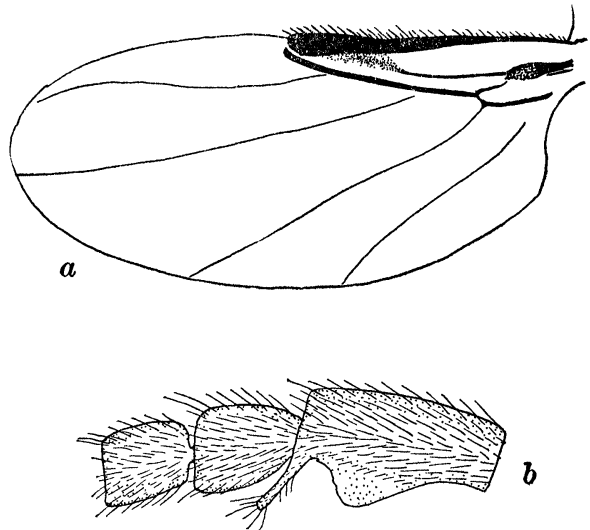

Fig. 1. Coniceromyia cubensis sp. nov. $a$, wing; $b$, base of front tarsus.

lowish brown; halteres white; palpi yellow. Wings hyaline, with a brownish tinge, stronger toward the costa, the costa at extreme base and most of the first vein yellow. Front shining, one-fourth broader than high; with a fine, clearly impressed median line; ocelli on a raised triangle. Bristles large and strong; two post-antennals very close together, reclinate and slightly divergent, about half as large as the other bristles; lower frontal series of four equidistant, their bases forming a line which curves gently downwards medially; upper frontal row forming a similarly curved series, the median pair a little closer to one another than to the lateral bristle; they are placed high on the front, so that the median pair form an equilateral triangle with the anterior ocellus; ocellar row of four. Eyes distinctly pubescent; postocular cilia strong. Cheek with three, large, downwardly 
directed macrochætæ; palpi with moderately short bristles. Third antennal joint pyriform, pointed at tip, three-fourths as long as the eye; arista terminal, as long as the antenna. Mesonotum shining, with one pair of dorsocentral macrochætæ. Scutellum nearly half as long as wide, with four marginal bristles; one bristle above and several below the prothoracic spiracle. Mesopleura entirely bare. Front tibiæ simple, not notched, nor emarginate, with a series of three large bristles, one at the basal fifth, another at the second fifth and the third just beyond the middle; all tarsal joints widened, the first with a triangular extension along the inner edge and a slender, projecting process at the tip (Fig. 1, $b$ ) as in $C$. anacleti Borgm. Middle tibia with a pair of very large bristles near the basal fourth on the posterior surface and another, not quite so large externally before the tip. Hind tibia with one large bristle just before the middle behind, one externally at apical fourth and three terminal spurs. Abdomen large, dull above, with none of the segments lengthened. Costa half as long as the wing, (Fig. 1, a) its bristles very short and closely placed, very slender at base gradually thickened beyond and very broad at apex; first vein thickened just before tip; third vein stout, of even thickness; fourth vein unusually close to the costal margin, slightly curved at base; fifth, sixth and seventh veins nearly straight.

Female. Length $1.3 \mathrm{~mm}$. Similar to the male, except that the antennæ are small, oval, with dorsal arista and the fore tarsi are simple, with the second to fifth joints slightly broadened.

Types from the San Juan Mts. near San Blas, Province of Santa Clara, Cuba, February 1927.

The female is very much smaller than the male, but this undoubtedly represents only individual variation as there are no morphological differences aside from the secondary sexual characters of the antennæ and front tarsi.

As indicated in the preceding key, this species is distinguishable from the three known South American species by the presence of a series of three large bristles on the anterior tibia; from $C$. anacleti and C. epicantha by its dark color, and from $C$. fusca and $C$. epicantha by the appendage of the first tarsal joint of the front leg. This peculiar structure is present in $C$. anacleti. 

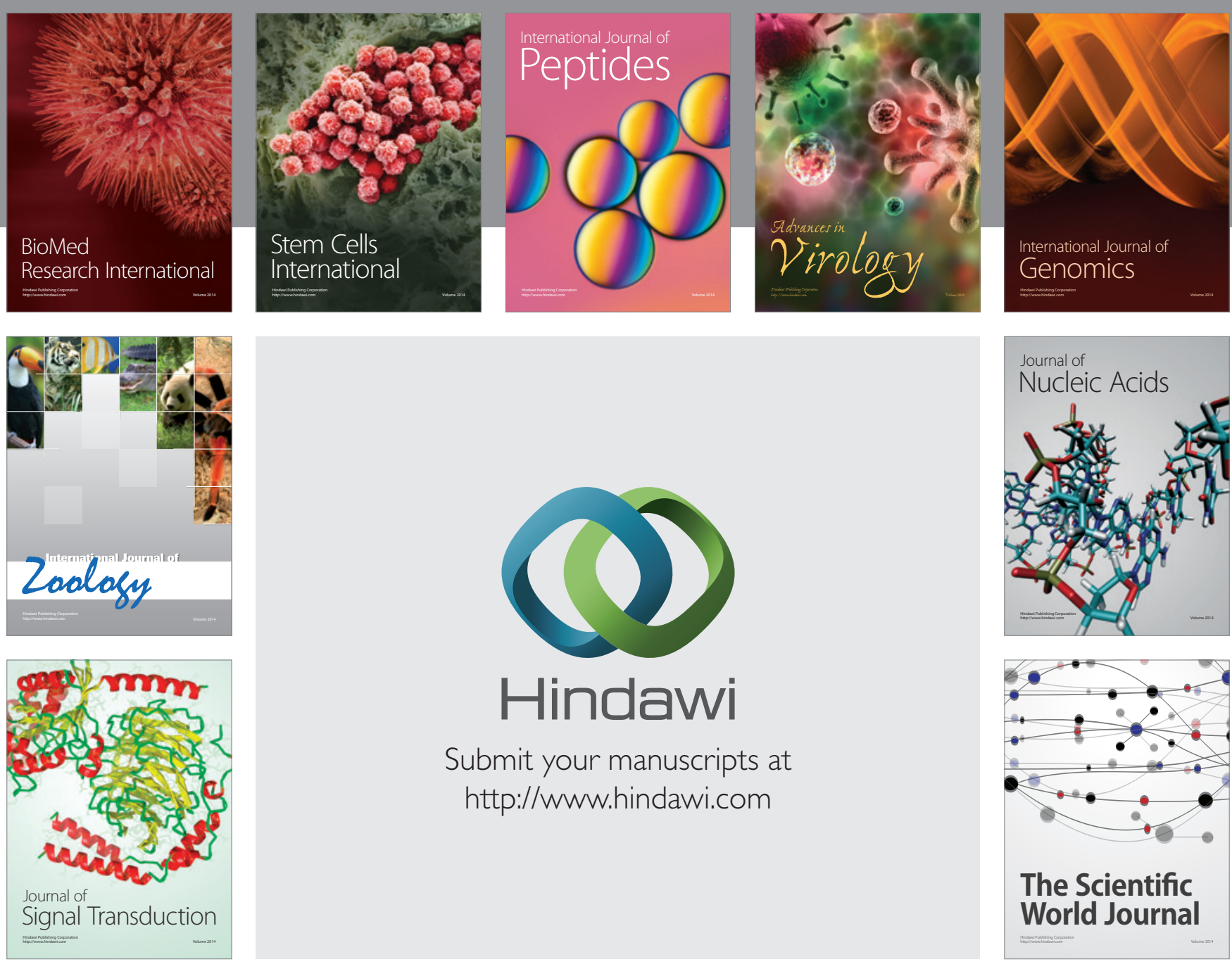

Submit your manuscripts at

http://www.hindawi.com
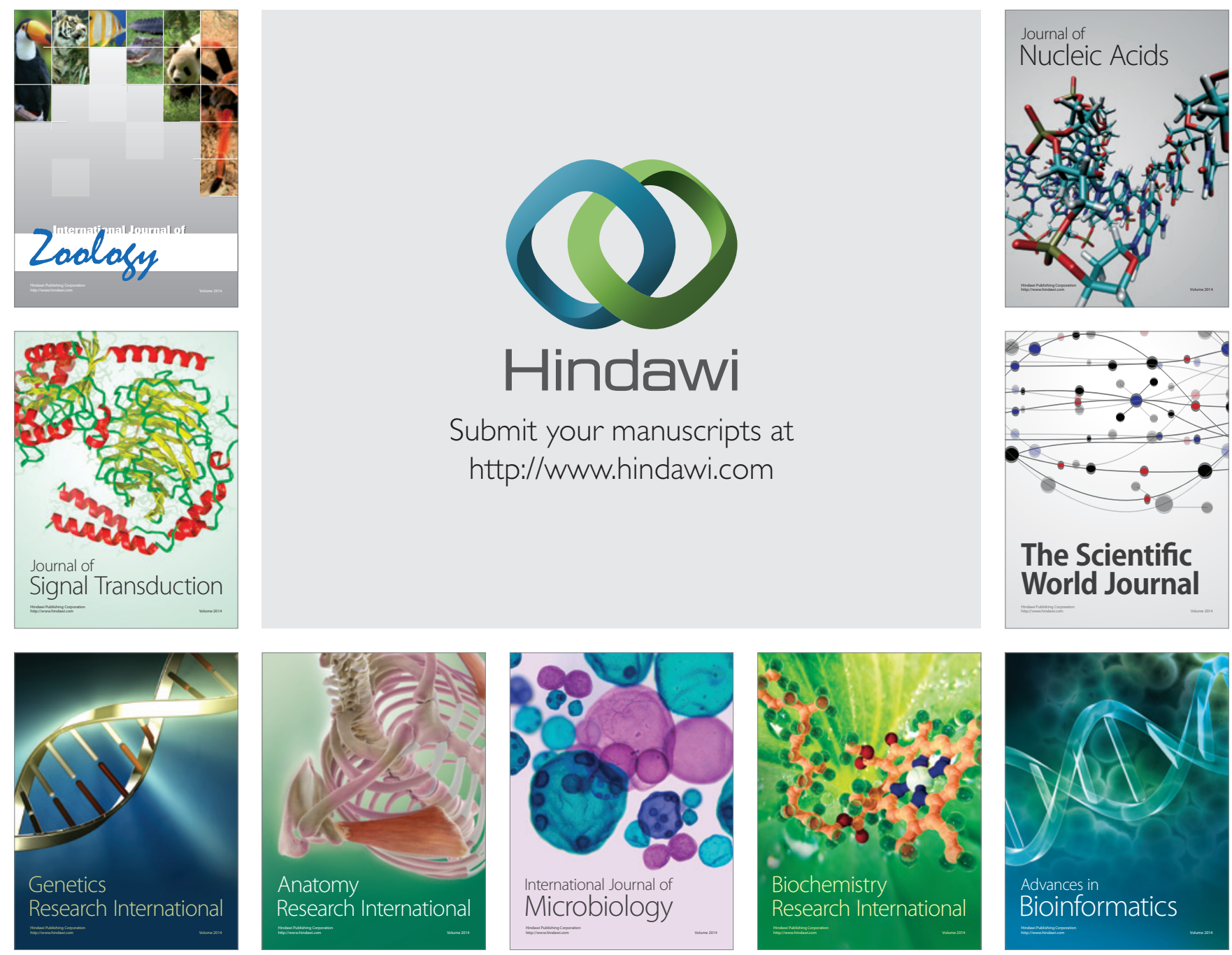

The Scientific World Journal
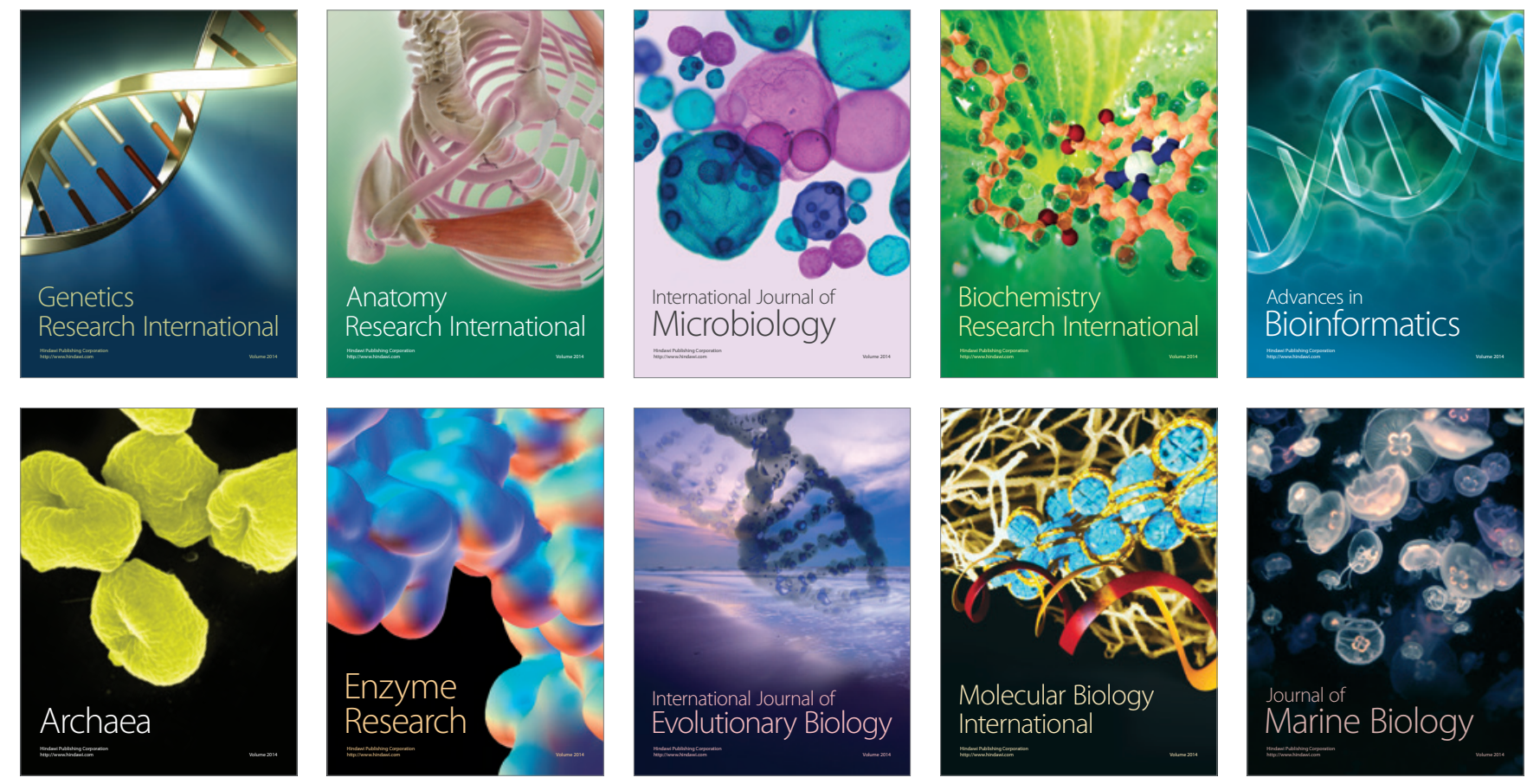